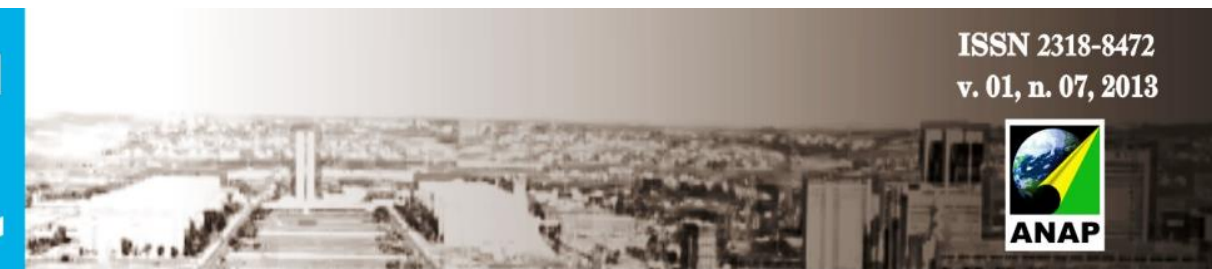

\title{
REGULARIZAR A PARTICIPAÇÃO POPULAR PODE SER A SAÍDA PARA A ATUAL CRISE DA DEMOCRACIA REPRESENTATIVA
}

\author{
Andréa Alves Araújo'
}

Camilo Michalka Jr. ${ }^{2}$

RESUMO: Este artigo propõe uma reflexão sobre a viabilização do preceito constitucional de participação popular em todos os canais decisórios do Estado. Para dar início a ponderação, parte-se da teoria de Robert A. Dahl (2005), de que é necessário viabilizar a participação popular em todos os processos de tomada de decisão para se promover a efetiva institucionalização dos procedimentos e a devida ampliação das atuais parcelas atuantes da população. O objetivo deste é o de refletir sobre a importância da participação popular no combate da atual crise de representatividade do modelo político brasileiro, com foco no cidadão comum e na sua possível intervenção nos processos decisórios locais. $A$ presente pesquisa se estruturou em análises comparativas e no exame das aparentes fragilidades do tema para concluir que uma sociedade só será verdadeiramente

1 Bacharel em Ciências Econômicas pela UGF/RJ; graduada em Comunicação Social/Jornalismo pela FACHA/RJ; especialista em Ciências Ambientais pelo NADC/UFRJ; e mestranda em Engenharia Urbana pela Escola Politécnica da Universidade Federal do Rio de Janeiro (PEU/POLI/UFRJ). E-mail: andreaaraujo@poli.ufri.br.

2 Engenheiro Civil pela UFRJ, Mestre em Engenharia Civil pela COPPE/ UFRJ, Doktor-Ingenieur pela Universität Stuttgart (US/Alemanha) e bolsista de Pós-doutorado no exterior pelo CNPQ. É professor associado da Escola Politécnica da Universidade Federal do Rio de Janeiro (POLI/UFRJ), membro efetivo dos cursos de extensão e do Programa de Mestrado Profissional em Engenharia Urbana (PEU/POLI/UFRJ) e coordenador do Laboratório de Estudos Estratégicos e Ambientais (LEEAmb/UFRJ). E-mail: michalka@poli.ufri.br . 

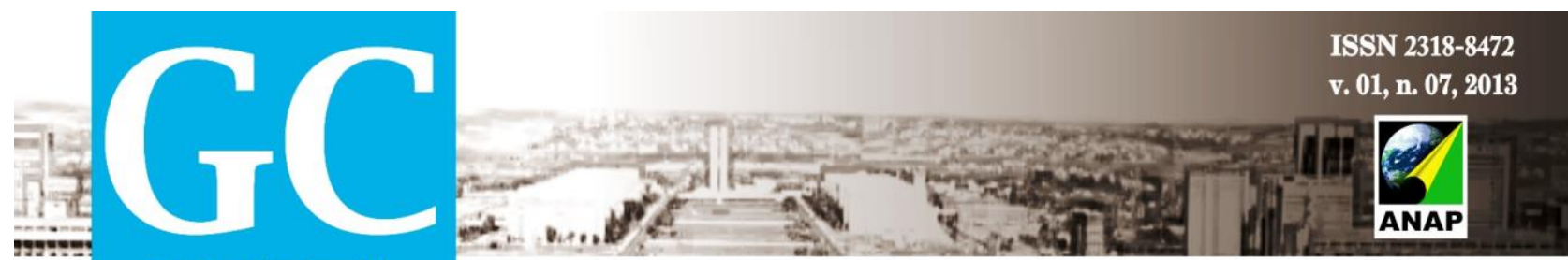

Revista Nacional de

Gerenciamento de Cidades

democrática se a sua população participar efetivamente das decisões quanto aos assuntos de interesse comum.

Palavras-chave: Cidadania. Representatividade política. Tomada de decisão.

\section{INTRODUÇÃO}

Em meio à crise mundial de representatividade democrática, o Brasil está a caminho de mais um ano de eleições. Nas ruas, manifestações e greves dificultam o inicio do período de discursos em palanques e a divulgação de plataformas e promessas políticas. A compreensão das fragilidades que cercam 0 atual modelo de representatividade política deixou de ser uma tarefa complexa, uma vez que desfavorece a participação da sociedade nos processos decisórios e se revela pela falta de regularização ${ }^{3}$ e de regulamentação ${ }^{4}$.

Este artigo parte da visão do cientista político norte-americano, Robert A. Dahl $(2005)^{5}$, de que a viabilização do preceito constitucional de participação popular em todos os canais decisórios do Estado é fundamental para se obter a efetiva institucionalização dos seus procedimentos e respectiva ampliação de parcelas da população tradicionalmente excluídas dos processos de tomada de decisão.

O objetivo deste texto é o de refletir sobre a importância da participação popular nos processos decisórios urbanos e no combate da atual crise de representatividade governamental.

${ }^{3}$ Regularização é "ato ou ação de regularizar, tornar-se regular, normal ou ordenado" (AULETE DIGITAL, 2013).

4 Regulamentação é o "conjunto de disposições legais concernentes a uma atividade, instituição, etc." (AULETE DIGITAL, 2013).

${ }^{5}$ Robert Alan Dahl é professor emérito de ciência política na Universidade de Yale, nos Estados Unidos da América. É um dos mais destacados cientistas políticos em atividade e um dos maiores expoentes da reflexão sobre as condições e os processos da política democrática contemporânea. 

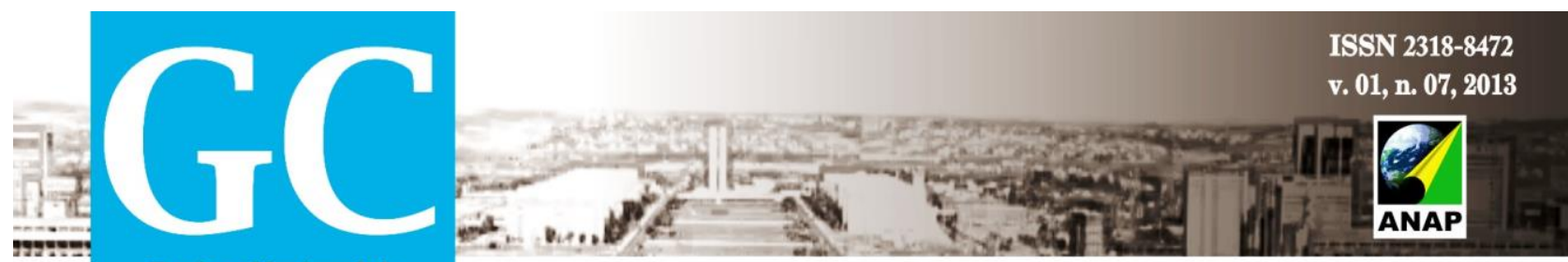

Revista Nacional de

Gerenciamento de Cidades

\section{A IMPORTÂNCIA DA PARTICIPAÇÃO}

Em qualquer sistema verdadeiramente democrático, a participação é um dos pilares da democracia. Em sentido amplo, participar é intervir, influenciar e interferir em um processo decisório. O princípio da participação cidadã surge como fundamento da soberania popular e encontra-se implícito no ordenamento constitucional brasileiro pela sua essencialidade democrática.

Existem múltiplas dimensões de participação. Por exemplo, ela pode ser plena, quando se dá de forma direta, ou minimalista, quando se constata que há um déficit de participação nos processos que modificam e ampliam as relações de poder. Nesse caso, ela acabaria por gerar uma crise de legitimidade e de governabilidade.

A participação é um importante instrumento para o aprofundamento da democracia que, a partir da descentralização, faz com que haja maior dinâmica na participação, principalmente no âmbito local. Ainda assim, a democracia possui um dilema recorrente que é a falta de participação popular nos processos decisórios do Governo, onde o princípio da representatividade tem sido a solução.

De acordo com Robert A. Dahl (2009), a democracia é um processo. Ela é fruto da competição e da participação que se estabelece a partir de um equilíbrio de forças. Ou seja, é o "equilíbrio de atores políticos inseridos em uma relação estratégica". (DAHL, 2005, p. 19).

Para Dahl, para que o governo possa satisfazer a exigência de que todos os membros de uma sociedade que estejam igualmente capacitados a participar de decisões sobre sua política, os seguintes critérios devem existir:

i. Participação efetiva: todos os membros devem ter oportunidades iguais e efetivas de fazer os outros conhecerem suas opiniões;

ii. Igualdade de voto: todos os votos devem ser contados como iguais;

iii. Entendimento esclarecido: todos devem ter oportunidades iguais de aprender política e suas consequências;

iv. Controle do programa de planejamento: os membros devem ter a oportunidade exclusiva para decidir como, quais e quando as questões devem ser colocadas em planejamento; e 

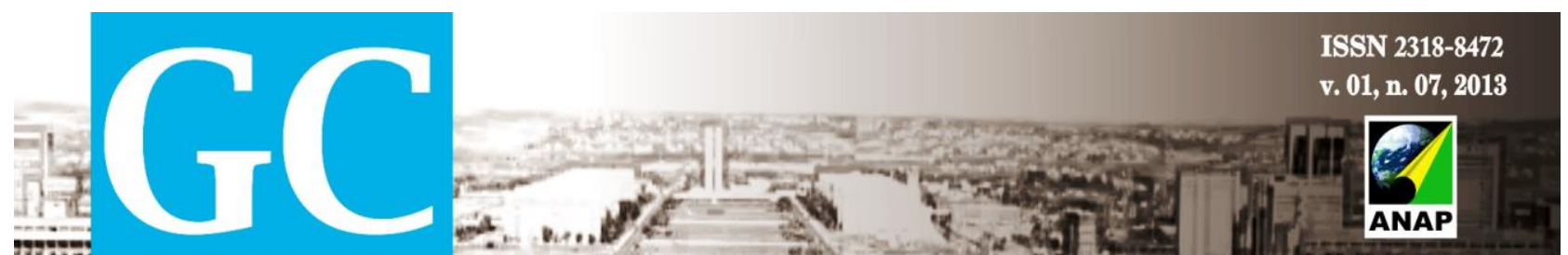

Revista Nacional de

Gerenciamento de Cidades

v. Inclusão dos adultos: todos os adultos possíveis, residentes e permanentes, devem ter plenos direitos de cidadão (DAHL, 2009, p. 49/50).

Para que a ordem política tenha o caráter democrático, é primordial que a população também possa decidir sobre os temas que serão objetos de deliberação do Estado.

Hoje, não há dúvidas quanto à essencialidade da participação cidadã para se estabelecer a democracia urbana, redistribuir e redefinir poderes antes apenas alocados nas mãos de uma pequena elite econômica, política e cultural. Desse modo, "[...] ao chegar a decisões, o governo deve dar igual peso ao bem e aos interesses de todas as pessoas ligadas por tais decisões" (DAHL, 2005, p.78).

A participação popular, enquanto processo histórico e social está sempre em eterna mutação e reconstrução por redefinir e redistribuir poderes e deveres. Segundo Dahl (2005), "a participação da população nos processos decisórios se constitui num sistema frágil que ainda está em construção". Nesta perspectiva, a igualdade intrínseca, além de se mostrar um princípio moral razoável à fundamentação do governo de um Estado democrático representativo, tende a romper com o argumento da tutela política no qual se inscreve a ideia de que as pessoas comuns não têm competência para governar. De modo que ele faz um alerta:

[...] há necessidade de que se desenvolva efetivamente a institucionalização dos procedimentos e a ampliação da participação popular, sendo que, para isso, devem ser viabilizados todos os canais de participação da população na tomada de decisão do Estado. (DAHL, 2005).

A participação da população em um estágio decisivo possibilita e assegura a cada cidadão a igualdade de expressão e de escolha em qualquer instância, através de audiências públicas, plebiscitos, abaixo-assinados, ações populares, projetos de lei de iniciativa popular etc. Todo tipo de manifestação da vontade da população pode ser utilizado, desde que o Poder Público federal, estadual ou municipal fique atento às 

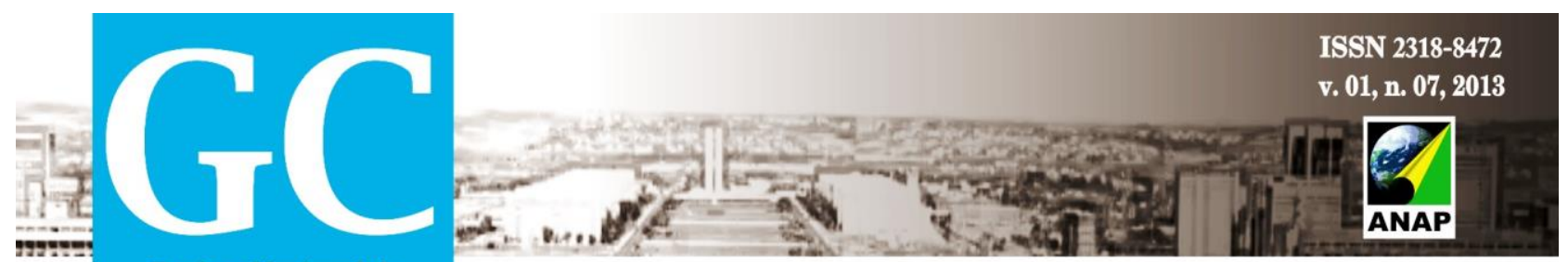

Revista Nacional de

Gerenciamento de Cidades

demandas populares e atenda às reivindicações da forma mais democrática possível. (DOWBOR, HOUTZAGER e SERAFIM, 2008)

A cidadania, segundo Manzini-Covre (2001, p. 10), é a prática da reivindicação de direitos e deveres. Ela é uma via de mão dupla. Ou seja, uma via onde representantes e representados têm responsabilidades na construção de uma representação de qualidade, embora a qualidade exercida não dependa somente do empenho dos representantes em prestarem contas e em buscarem informações. Ela depende também da capacidade do grupo de fornecer as informações necessárias para a sua representação e de exigir a prestação de contas.

Em outras palavras, cada representante tem suas próprias opiniões e direito a valores, princípios e opiniões próprias. Todavia, enquanto representante, o seu papel é o de falar em nome da coletividade representada. Para isso, ele precisa desenvolver maneiras de se informar sobre as opiniões dos representados, o tema a ser debatido e decidido, prestar constas de sua atuação e informar ao coletivo as discussões das quais participa. (DOWBOR, HOUTZAGER e SERAFIM, 2008) Além disso, o representante precisa ter autonomia no momento da negociação, pois ele poderá se deparar com situações não previstas, em que precisará negociar outras maneiras de contornar os problemas enfrentados por seu grupo, segmento ou região. Dada à autonomia, existe outro risco: o do representante se distanciar de seu grupo. Para minimizar isso, ele precisa prestar contas de sua atuação, explicitar e justificar os motivos das decisões que tomou.

Representar uma demanda ou opinião de um grupo, nem sempre é uma ação automática, porque as condições reais para concretizar um ideal podem ser bastante diferentes do desejado. Consequentemente, o representante precisa ter autonomia para poder se mover num universo de possibilidades concretas recortadas pelas negociações e marcadas pelos contextos, que são os espaços de representação. 

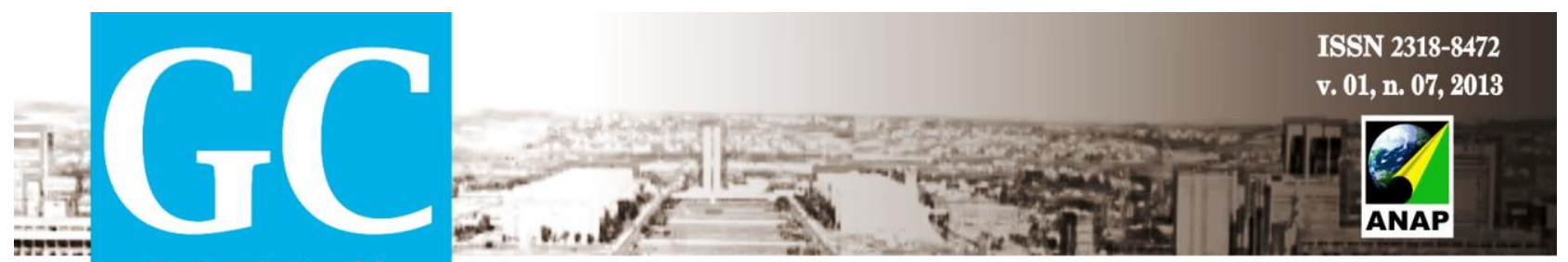

Revista Nacional de

Gerenciamento de Cidades

Se a representação democrática perder o contato com os anseios e as necessidades da população representada, fazendo-se refém de interesses corporativos poderosos, os cidadãos perderão a sua forma de participação política.

Promover a participação dos mais pobres e de suas comunidades na vida política e nos processos de tomada de decisão tornou-se um desafio para as políticas de inclusão social e de melhoria dos serviços públicos no país. Principalmente, porque a conquista da opinião pública depende da capacidade de realização e da abertura do governo à participação da sociedade na gestão pública, garantindo a transparência, a publicidade, a eficiência, a agilidade e a eficácia das ações de governo.

\subsection{OS PRINCÍPIOS E DILEMAS}

A participação é um princípio inerente à democracia, que favorece a qualidade de vida urbana e $\mathrm{o}$ atendimento às demandas dos cidadãos. Por conseguinte, os seus procedimentos precisam denotar e constituir significados conhecidos e conscientes para a maioria da população. Ou seja, a falta de participação direta - que é aquela em que os cidadãos não delegam o seu poder de decisão - é uma realidade que precisa ser alterada, pois ter direito às cidades e ao desenvolvimento sustentável ${ }^{6}$ é uma função social urbana, isto é, uma função que se traduz em ter direito à habitação, saúde, saneamento, transporte, educação e a todos os demais serviços e benefícios infraestruturais para as presentes e as futuras gerações.

A participação da sociedade civil como meio para a construção de relações mais simétricas, dependeria da constituição de uma nova cultura política, capaz de contribuir

${ }^{6} \mathrm{O}$ conceito de "desenvolvimento sustentável" utilizado aqui equivale àquele que "satisfaz as necessidades do presente, sem comprometer a capacidade das gerações futuras de suprir suas próprias necessidades". (WCDE, 1987). 


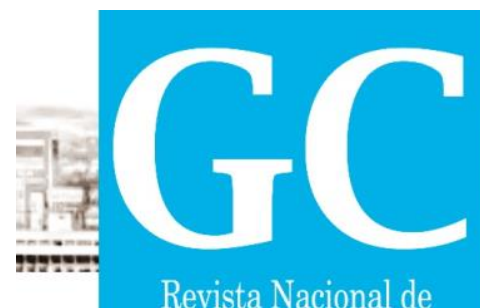

Gerenciamento de Cidades
ISSN 2318-8472

v. $01, \mathrm{n} .07,2013$

para a construção de um processo, segundo Santos e Avritzer (2002), de emancipação social, utilizando-se a concepção contra-hegemônica de democracia.

À medida que o Estado, através da instituição de mecanismos de participação popular, pretende inserir outros atores na tomada de decisão sobre as políticas pública, deve estar disposto por livre e espontânea vontade também a estabelecer relações menos desiguais. Neste sentido, Santos Junior (2001) destaca que:

[...] as desigualdades sócias geram situações de assimetrias de poder e de desigualdades de condições de participação social [...]. No entanto, apesar das limitações, os governos locais podem intervir para ampliar o acesso dos cidadãos aos direitos sociais e políticos e habilitar, assim, os grupos em situação de desvantagem social. (SANTOS JUNIOR, 2001, p. 105)

A participação popular como meio para a construção de relações mais simétricas, pode passar pelo que Santos (apud LEITE, p. 60, 2007) chama de "constelação de práticas e relações emancipatórias". Para Leite (2007):

Mesmo sabendo que algumas relações de poder são muito desiguais e arraigadas às práticas políticas, as relações emancipatórias estariam se estabelecendo no interior das relações de poder, construindo cada vez mais um número maior de relações mais iguais. (LEITE, 2007, p. 60)

Segundo Leite (2007), os processos participativos podem, inclusive, reforçar as relações desiguais:

[...] ao invés de reforçarem relações emancipatórias, os processos participativos frequentemente vêm sendo utilizados para reforçar as relações desiguais, através do uso de energia por parte dos atores com maior poder econômico e político. Especialmente nos processo que têm como foco a discussão do espaço urbano, são diversos os interesses que podem interferir na construção da participação, muitos destes expressos a partir do próprio Estado, como os interesses dos proprietários de terra, do setor da construção civil e até de investidores internacionais. (LEITE, p. 60, 2007)

No entanto, a participação popular visa estabelecer parcerias entre Estado e sociedade civil, para que, juntos, possam atingir o objetivo desejado por todos, que é a melhoria das condições de vida de toda a população.

A Constituição da República assegura a soberania popular nos seguintes termos: "Todo o poder emana do povo, que o exerce por meio de representantes eleitos ou 

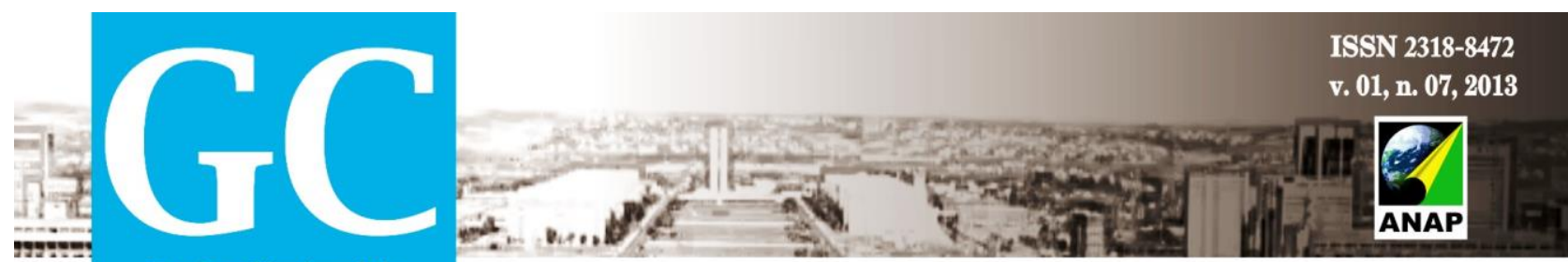

Revista Nacional de

Gerenciamento de Cidades

diretamente" (art. 1ํ, parágrafo único). É com essa inspiração que a democracia brasileira se assenta em dois pilares: a representação e a participação popular. Pelo princípio representativo, o eleito pratica atos em nome do povo (participação indireta). $\mathrm{Na}$ democracia participativa, o povo exerce diretamente a sua soberania.

\subsection{OMISSÃO E COBRANÇA: UMA CONTRADIÇÃO DE NOSSA SOCIEDADE}

Outro lado da questão é a disposição dos cidadãos à participação. Com a frase "não gosto de política", ou "não quero saber de política", os cidadãos se omitem, abrindo mão de seu direito à participação.

Participação exige disponibilização de tempo para se informar e formar opinião. Exige também tempo para reuniões, para ouvir opiniões e para expressar as suas. Formar opinião é uma tarefa individual. Trazer para si a capacidade de ouvir e de se fazer entender.

Para tal, é fundamental o respeito às opiniões contrárias. Entender essas opiniões e enriquecer os próprios argumentos. Aprender que não está havendo uma disputa "para ver quem ganha". A importância das argumentações é a de poder chegar à melhor decisão e condução de um processo decisório. A decisão deve contemplar a melhor solução que seja viável.

Nesse ponto também é inerente ao processo, poder definir planejamento de curto, médio e longo prazo, com o objetivo de atingir metas decidas. Os indivíduos, na sociedade brasileira, ainda estão num processo inicial definição de participação da sociedade. Seja por parte dos cidadãos, seja por parte daqueles que eles escolhem para representá-los.

Para muitos, a participação se encerra no momento de votar. Para ilustrar essa afirmação, destacam-se dois exemplos: um no âmbito acadêmico; e outro, em situação de necessidade de tomada de decisão. 


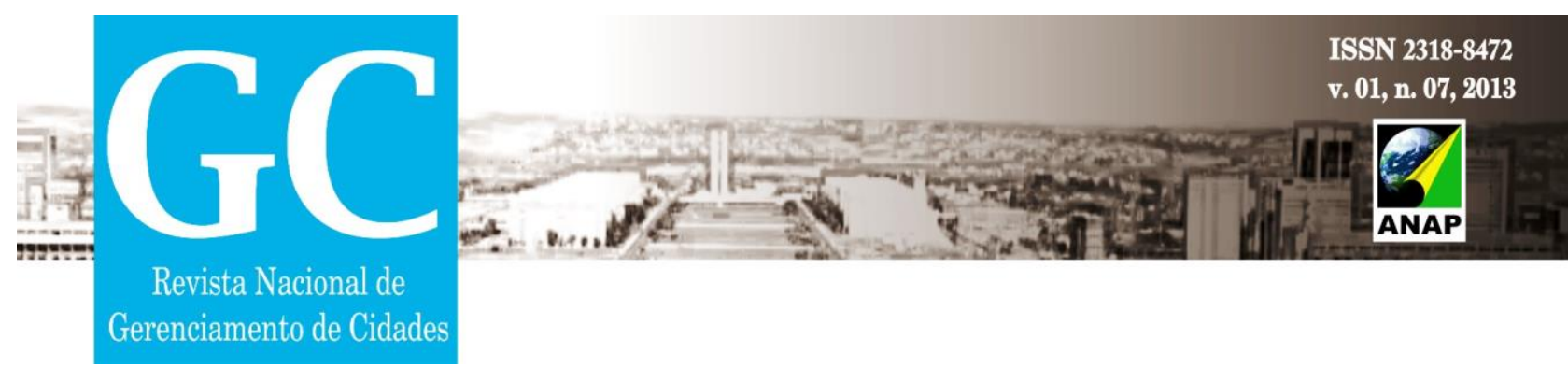

No acadêmico, temos a universidade pública que é constituída por diversos colegiados. Inicialmente, existem os departamentos, onde todos têm o direito à participação. O departamento é a instância onde todos têm voz. Os demais colegiados são compostos por membros natos e eleitos. A função dos membros eleitos é a de assumirem a posição dos seus representados. Para tal, é fundamental que 0 representante faça reuniões com os seus pares para definir posições, pois ele está ali para emitir a opinião e posição dos representados e não as próprias.

O representante eleito tem por obrigação defender a posição daqueles a quem representa, mesmo que a sua posição pessoal seja diferente das demais. Raras são as reuniões para discutir posicionamento. O mais comum, é que o representante acabe por expressar as próprias opiniões e posicionamentos pessoais. Mas, o mais grave ocorre quando o representante não procura saber a opinião dos seus representados e/ou ocorre a omissão dos representados, que não exigem serem ouvidos. Esse procedimento é igual ao que ocorre nas eleições para representantes públicos municipais, estaduais e federais, sejam eles vereadores, deputados, senadores, presidentes ou dirigente eleitos. De modo que, mesmo que haja a vontade do representante em se reunir com os seus representados, poucos são aqueles que se dispõem a arranjar tempo para discutir a tomada de decisão.

Como exemplo de ausência voluntária no processo de decisão, destaca-se a reunião/assembleia de condomínio. A reunião de condomínio tem a finalidade de analisar as necessidades e definir as prioridades do coletivo, além de planejar os meios financeiros necessários para as respectivas execuções. Nas assembleias também são apresentadas as contas e os membros da administração (síndico, subsíndico e comissões), com antecedência legal, para aprovação e eleição. Mas, embora relevantes, o que se verifica, em geral, é que o número de presenças é menor que o número de condôminos com direito a voto; inclusive, dos mais ferrenhos críticos à administração.

A nossa sociedade tem se pautado pela omissão e crítica, muitas vezes, vazia. No entanto, o exercício da cidadania exige envolvimento e informação para fundamentar 

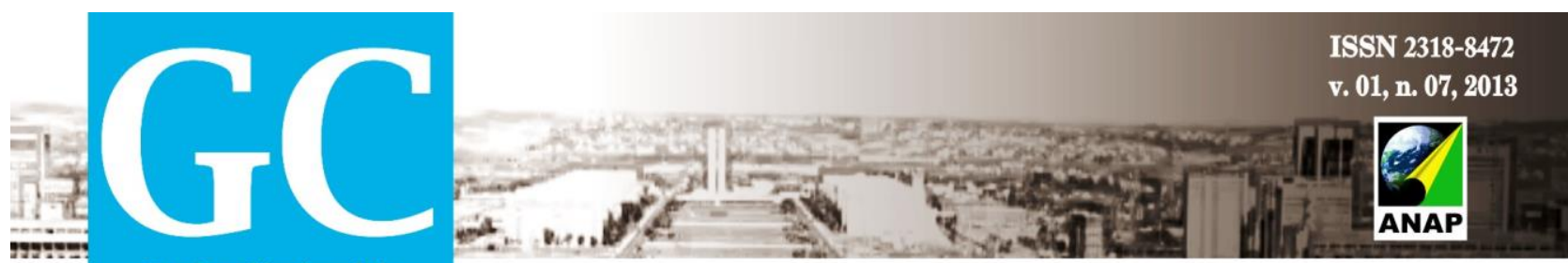

Revista Nacional de

Gerenciamento de Cidades

opiniões e críticas. A ausência de participação e da necessária busca pela informação fornece aos representantes meios para decidirem mediante a "força em que o vento sopra". Ou seja, o cidadão, ao não se envolver nos processos decisórios que the são de direito e dever, sede o seu direito a outros, mais organizados e atuantes, de fazê-lo.

\subsection{A PARTICIPAÇÃO NA CIDADE}

O local mais propício para o exercício da democracia é o município, que é onde as decisões mais próximas da comunidade ocorrem e onde o indivíduo tem maior poder de influência nessas decisões. Entretanto, poucos são os municípios que desenvolvem a participação num sentido democrático mais concreto, por meio da participação popular na administração pública.

Os municípios, em geral, enfrentam muita dificuldade com a gestão cotidiana dos processos de ocupação e crescimento urbano, como: problemas ambientais decorrentes de ocupação indevida; tensões em torno do solo urbano envolvendo diferentes classes sociais; conflitos relativos à convivência de usos; até a proliferação de ocupações irregulares e em situação de risco. Todavia, cabe ao município a responsabilidade de promover o adequado ordenamento do seu território e isso se dá por meio de planejamento e controle do uso do solo, com a divisão e a ocupação do solo para as atividades econômicas, sociais e de interesse público. É o que prevê os artigos 30 , inciso III, e 182, § 2º, da Constituição de 1988.

O Estatuto da Cidade, Lei Federal № 10.257/2001, obriga a prefeitura e a câmara municipal a abrir espaço para que todos participem das decisões sobre a cidade. Além disso, ele fornece as regras gerais para o planejamento de todas as cidades nacionais, enquanto que o Plano Diretor diz quais regras serão usadas em cada município, de modo a organizar o seu crescimento e funcionamento. 

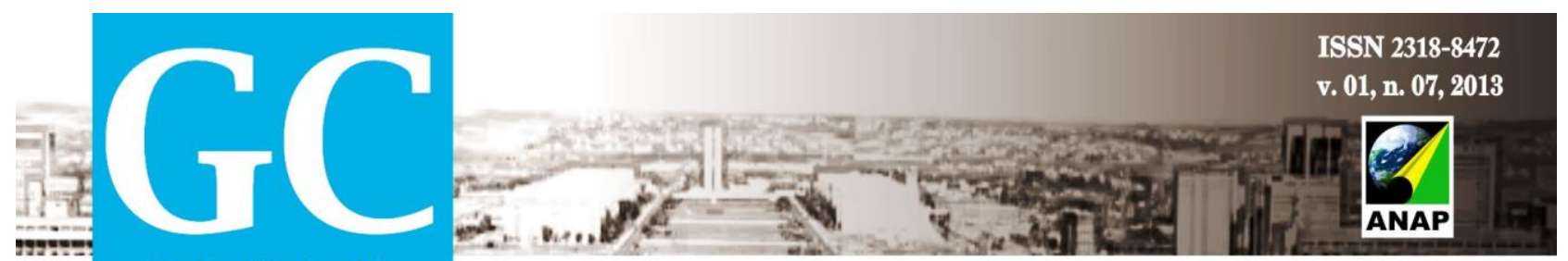

Revista Nacional de

Gerenciamento de Cidades

A participação social é assegurada pelo inciso II do artigo 2ํ․ Estatuto da Cidade, Lei Federal № 10.257/2001, onde a população e as associações representativas de vários segmentos da comunidade acompanham a formulação e a execução de planos, programas e projetos de desenvolvimento urbano. A participação ou gestão democrática permite a consolidação de um território que venha assegurar a cidadania, permitindo a inclusão produtiva das populações pobres dos territórios, a busca da universalização de programas básicos de cidadania e o planejamento e integração de políticas públicas.

O Estatuto da Cidade promove a participação popular através:

- da gestão democrática na formulação, execução e acompanhamento de planos, programas e projetos de desenvolvimento urbano (art. $2^{\circ}$, II);

- o controle social na utilização dos instrumentos que implicarem dispêndio de recursos públicos municipais (art. 4ํㅗ $\S 3^{\circ}$ );

- no monitoramento de operações urbanas (art. 33, VII);

- a participação na discussão do plano diretor (art. 40, § 4º, I);

- na gestão da cidade, no que respeita à formulação do orçamento participativo, do plano plurianual, da lei de diretrizes orçamentárias, do orçamento anual e nas atividades dos organismos gestores das regiões metropolitanas e aglomerações urbanas (arts. 43 a 45).

Contudo, o problema persiste, uma vez que, frequentemente, a população só toma contato com as regras de sua cidade quando descobre que não pode construir em um determinado lugar ou que seu endereço ou rua não existe oficialmente para a sua prefeitura. E o pior é que sem participar, a população não se sente responsável pela cidade.

Portanto, a sociedade não deve esperar passivamente que os órgãos públicos viabilizem a participação popular em suas cidades. É seu o papel de organizar-se para o exercício efetivo da cidadania, utilizando-se do legítimo direito do poder de pressão que, ao mesmo tempo, dá força ao Estado para que ele promova rupturas com formas 

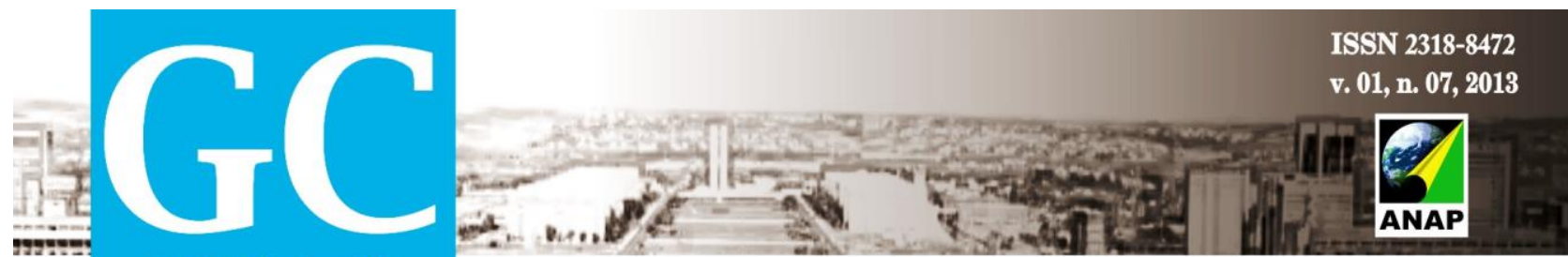

Revista Nacional de

Gerenciamento de Cidades

tradicionais de governo e as políticas que só favorecem as elites. Visto que, a falta de participação também faz com que aqueles que desejam uma cidade melhor não possam torná-la real.

\section{CONCLUSÃO}

Este ensaio sobre o tema proposto permite afirmar que, hoje, o maior obstáculo para uma mudança significativa no atual modelo de representatividade política brasileira advém do fato dos próprios cidadãos estarem abrindo mão de participar dos processos de tomada de decisão do Governo. Agrega-se a isso, a crescente necessidade de um maior posicionamento do cidadão urbano aos processos decisórios das cidades, ou seja, do local onde vive, conhece e deseja.

Diante da constante ameaça que vivemos ao preceito constitucional de participação popular, resultado da supremacia dos interesses privados e individuais sobre os sociais e coletivos, o cidadão urbano precisa interagir e tornar-se agente da própria cidade. Caso contrário, infere-se que o mais provável seja que outros poderão controlá-la e administrá-la, visando somente o lucro imobiliário, monetário, individual.

$\mathrm{Na}$ verdade, se por um lado criam-se mecanismos que permitem e fomentam a participação da sociedade civil nos processos de tomada de decisão urbana; por outro, avolumam-se meios que facilitam a negação e o distanciamento dos mesmos. E como a democracia só é plena com a participação dos cidadãos; cabe aqui destacar um pequeno trecho do Handbuch zur partizipation (Manual para a participação):

Toda democracia depende da participação das pessoas. Ela só pode ser viva, se o maior número de cidadãos estiver disposto a se engajar. O termo participação abrange todas as iniciativas, medidas, modelos e métodos que permitam uma 

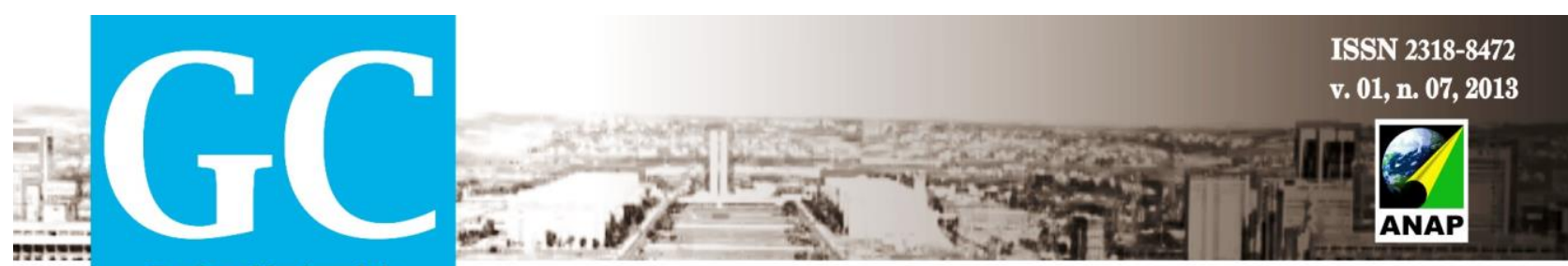

Revista Nacional de

Gerenciamento de Cidades

atuação democrática no processo de decisão ${ }^{7}$. (SENATSVERWALTUNG FÜR STADTENTWICKLUNG UND UMWELT BERLIN, 2012, p. 14)

Afinal, uma sociedade só será verdadeiramente democrática se a sua população participar efetivamente das decisões quanto aos assuntos de interesse comum.

\section{REFERÊNCIAS}

AULETE, A. C. Dicionário Aulete Online. Lexikón Editora Digital, 2013. Disponível em: http://aulete.uol.com.br/site.php?mdl=aulete digital Acesso em: 13 ago. 2013.

DAHL, Robert A. In. PACIORNIK, Celso Mauro (trad.). Poliarquia: participação e oposição. São Paulo: Edusp, 2005. (A 1ํㅡㄹ edição é de 1997 e a original, em inglês, de 1971).

Sobre a Democracia. $2^{\underline{a}}$ ed. Brasília: UNB, 2009.

DOWBOR, Monica; HOUTZAGER, Peter; e SERAFIM, Lizandra. Enfrentando os desafios da representação em espaços participativos São Paulo: CEBRAP, IDS, 2008.

LEITE, Socorro. de Paula Barbosa Rodrigues. Participação popular e acesso à moradia as escolhas possíveis para a população removida por intervenções de melhoria urbana do PREZEIS. Recife: Ed. Universitária da UFPE, 2007.

MANZINI-COVRE, M. L. O que é cidadania. São Paulo: Brasiliense, 2001.

SANTOS JUNIOR, O. A. Democracia e governo local: dilemas da reforma urbana municipal no Brasil. Rio de Janeiro: Revan, 2001.

SANTOS, B. S. \& AVRITZER, L. Introdução: para ampliar o cânone democrático. In: SANTOS, B.S. (Org.). Democratizando a democracia: os caminhos da democracia participativa. Rio de Janeiro: Civilização Brasileira, p. 13-82, 2002.

\footnotetext{
7 Tradução livre de Camilo Michalka Jr.
} 


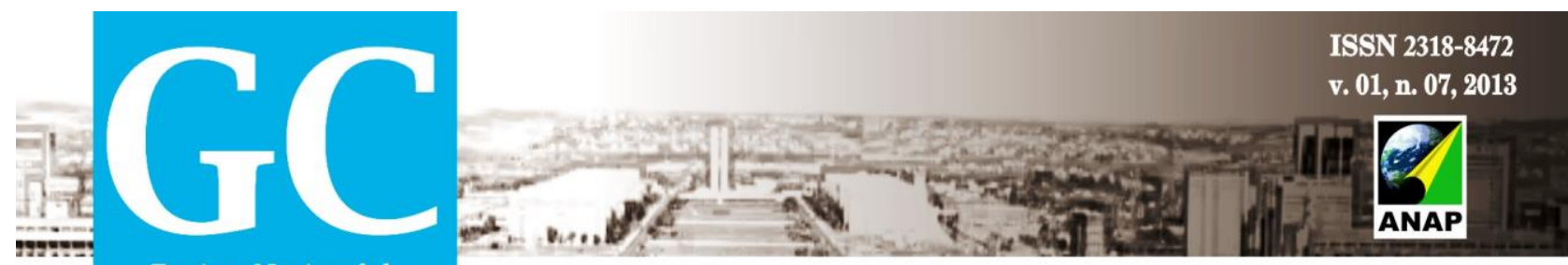

Revista Nacional de

Gerenciamento de Cidades

SENATSVERWALTUNG FÜR STADTENTWICKLUNG UND UMWELT BERLIN, Handbuch zur partizipation, segunda edição, 2012

WCED. Relatório Brundtland, Report of The World Commission on Environment and Development: Our Common Future, Chapter 2: Towards Sustainable Development, Geneva, Switzerland, ONU, 1987. Disponível em: http://www.un-documents.net/wcedocf.htm . 